\title{
Editorial
}

$$
\frac{1}{2}
$$




\section{¿Y si pluralizamos lo que entendemos como conocimiento y creación?}

Pedro Pablo Gómez Moreno

Universidad Distrital Francisco José de Caldas

ppgomezm@udistrital.edu.co

Cómo citar este artículo: Gómez, Pedro Pablo (2018). ¿Y si pluralizamos lo que entendemos como conocimiento y creación? Estudios Artísticos: revista de investigación creadora, 4 (4) DOI: https://doi.org/10.14483/25009311.12929 Villa de Leyva (2015). Fotografía: María José Arbeláez.
En los estudios artísticos la concepción de conocimiento está constantemente en juego. En ese sentido, su horizonte posible está directamente relacionado con la tensión que se da entre la idea que tiene la institución del arte sobre el conocer (o las ciencias que permean el campo del arte) y lo que finalmente dicen y hacen los creadores dentro y fuera de las artes. Por lo tanto, las definiciones teóricas e institucionales son interpeladas por las prácticas que en muchos casos hacen que las definiciones parezcan reductoras y precarias.

Ahora bien, lejos de estar planteando un dualismo entre teoría y práctica - que fue la base para la clasificación moderna de los seres humanos como pensantes, menos pensantes o carentes de capacidades sensibles y cognitivas - lo que quiero señalar es la dimensión teórica de las prácticas mismas $y$, en consecuencia, el carácter cognitivo inherente en todas las modalidades del hacer. Y no solo eso, el hacer no es cognitivo porque aplica o replica conocimientos, es cognitivo porque es creador de nuevos conocimientos que se hacen visibles en otros modos de hacer y formas sensibles cada vez más diversas y plurales.

De acuerdo con lo anterior, en vez de concebir el conocimiento como una singularidad, lo entendemos como una pluralidad, como la variedad de formas en las que se hace sensible la creatividad en el mundo. Esa creatividad es cada vez más diffcil de restringir al arte (del genio) o a la creatividad humana (del ingenio) a la manera del antropocentrismo moderno, debido a que la naturaleza en su inmanencia nos sorprende todo el tiempo con su capacidad creadora. Así, cada vez que nos encontremos con el conocimiento "en singular" podemos sospechar de su pretensión de universalidad 
y su riesgo ideológico cuando se pone al servicio de algún dispositivo del poder opresor. Así, visibilizar la pluralidad de conocimientos es clave para una justicia cognitiva mediante la cual será posible la des-clasificación de los seres humanos gracias al reconocimiento de su capacidad creadora.

En su pluralidad, los conocimientos son el acontecimiento no excepcional del senti-pensar en el mundo; son el alumbramiento constante mediante el cual la vida ilumina la noche del mundo. Este acontecer es posible gracias a la interacción, la inter-corporalidad, la colaboración, la escucha y la conversación entre las personas en y con la naturaleza (el entorno bio-físico). En esta concepción no se puede entender a la naturaleza como un objeto pasivo, mudo, insensible, saqueable, explotable, reducido a una inagotable fuente de recursos y energía, dispuesto para ser conocido. Por el contrario, la naturaleza concebida de manera positiva, es cuerpo-mundo-senti-pensante, substrato fundante y sensible de la vida. La naturaleza es la condición primera de derechos y sujeto de derechos, madre sintiente que habla, interpela y hace posible que la vida acontezca y en ese acontecer revela sus modos de ser, de aparecer, de estar y de existir. Esos modos de ser, aparecer, sentir, estar y existir son aprehensibles y expresables en una diversalidad de formas, como conocimientos. Los conocimientos, en consecuencia, no son otra cosa que la manifestación de las condiciones y avatares mediante los cuales la vida comparece a la existencia, florece y se conserva.

Dicho de otro modo, para los estudios artísticos, conocer no es interrogar, violentar, constreñir o disponer de un objeto como correlato de un sujeto que conoce; conocer son modos no violentos de relación, de creación, de conversación, de escucha, de sanación, de hacer, de estar, de ser, de sentir y de pensar-con, capaces de iluminar la convivencia social y cultural fundada en la interdependencia simbiótica de los seres humanos en y con la naturaleza.

Ahora bien, esta concepción del conocimiento no es precisamente la que prevalece en el mundo en que vivimos, donde la disputa por el conocimiento y su hegemonía es una señal de disputas más profundas por el control del poder de definición y significación del ser y no-ser de las personas y las cosas. Por tal razón, nuestra concepción se convierte en clave de un horizonte epistemológico distinto, caracterizado por un compromiso ético que pretende, poco a poco, ayudar a sanar las heridas históricas del ser, ocasionadas por los modos violentos, instrumentales y coloniales del conocer.

Y es precisamente en ese horizonte epistemológico y creador distinto en el que nos proponemos ubicar los artículos que componen este número de Estudios Artísticos. Como se podrá ver, cada autor desde sus propias prácticas nos hace pensar que ese horizonte que aquí hemos esbozado es un campo de expectativas posible y en plena emergencia.

\section{Referencias}

Gomez Moreno, P. (2015). Editorial. Estudios Artísticos, 1(1), 8-13. doi:https://doi.org/10.14483/25009311.10245

(2016). El horizonte formativo y el campo de expectativas de los estudios artísticos. Estudios Artísticos, 2(2), 8-13. doi:https://doi.org/10.14483/25009311.11524

(2017). La investigación-creadora o el horizonte ampliado de la investigación-creación. Estudios Artísticos, 3(3), 8-11. doi:https://doi.org/10.14483/25009311.12525 